\title{
El medio ambiente como víctima del conflicto armado en el departamento del Chocó*
}

\author{
The environment as a victim of the armed conflict in the department of Chocó \\ O meio ambiente como vítima do conflito armado no departamento de Chocó
}

DOI: https://doi.org/10.21803/pensam.v12i22.251

Edwin Samir Asprilla Panesso

https://orcid.org/0000-0001-8580-0506

Hames Yanier Lozano Urrego

https://orcid.org/0000-0001-6689-2281

Rafael Bechara Palacio

https://orcid.org/0000-0002-7995-8291

Ricardo Emiro Ledezma

https://orcid.org/0000-0003-3357-2884

\section{¿Cómo citar este artículo?}

Asprilla, E., Lozano, H., Bechara, R., \& Ledezma, R. (2019). El medio ambiente como víctima del conflicto armado en el departamento del Chocó. Pensamiento Americano, 12(23) 127-144. DOI: https://doi.org/10.21803/pensam.v12i22.251

\section{Resumen}

El departamento del Chocó es uno de los más biodiversos del mundo, pero también es uno de los más afectado por el conflicto armado que existe en Colombia, ya que el mismo presenta en alguna de sus sub regional constantes, masivas y sistemáticas violaciones a los derechos humanos que han marcado la macondiana realidad de este belloy rico departamento, para casos como la masacre del 02 de mayo de 2002 en Bojayá, donde hubo una gran cantidad de víctimas desde el componente persona, como el medio ambiente, lo último porque el rio, el bosque y demás componentes de esta diversidad sufrió afectaciones significativas tales como: contaminación del suelo, el aire, el agua y consecuente deforestación y devastación que causan los componentes químicos utilizados por los grupos armados al margen de la ley para combatir a sus enemigos. Se pretende visibilizar al medio ambiente como una víctima del mismo y los factores que nos permiten darle dicha connotación. Se usó el método hermenéutico basado en la revisión de doctrina, jurisprudencia y normas que reconocen al medio ambiente como un derecho. Es necesario que se aborde y se tenga en cuenta por toda la comunidad jurídicamente organizada llamado Estado Colombiano, incurso en concierto internacional que el medio ambiente debe ser tenido en cuenta como un derecho humano autónomo que es necesario para la vida, desarrollo de cada uno de los derechos y garantías de que gozan los asociados del Estado de Derecho hoy convencionalizado.

Palabras Clave: conflicto armado, deforestación, medio ambiente, minería ilegal, victima.

\begin{abstract}
The department of Chocó is one of the most biodiverse in the world, but it is also one of the most affected by the Colombian armed conflict, since it presents in one of its sub regional constant, massive and systematic violations of rights humans who have marked the macondiana reality of this beautiful and rich department, for cases such as the massacre of May 2 , 2002 in Bojayá, where there were a large number of victims from the person component, such as the environment, the last because the river, the forest and other components of this diversity suffered significant effects such as: soil, air, and water pollution; and consequent deforestation and devastation caused by the chemical components used by armed groups outside the law to combat their enemies. It is intended to make the environment visible as a victim of it and the factors that allow us to give it this connotation. The hermeneutical method based on the revision of doctrine, jurisprudence and norms that recognize the environment as a right was used. It is necessary to address and take into account by the entire legally organized community called the Colombian State, incurred in an international concert that the environment must be taken into account as an autonomous human right that is necessary for life, development of each of the rights and guarantees enjoyed by the associates of the rule of law today conventionalized.
\end{abstract}

Key words: armed conflict, deforestation, environment, illegal mining, victim.

*Artículo de reflexión. 


\section{Resumo}

O departamento de Chocó é um dos mais ricos em biodiversidade do mundo, mas também é um dos mais afetados pelo conflito armado que existe na Colômbia, já que o mesmo apresenta em alguma de suas sub-regionais constantes, massivas e sistemáticas violações aos direitos humanos que marcaram a macondiana realidade deste belo e rico departamento - como o massacre de 02 de Maio de 2002 em Bojayá, onde houve uma grande quantidade de vítimas humanas y ambientais porque $\mathrm{o}$ rio, o bosque e demais componentes desta diversidade foi afetado significativamente como: contaminação de solo, o ar, a água e a consequente deflorestação e devastação que causam os componentes químicos utilizados pelos grupos armados à margem da lei para combater a seus inimigos. Se pretende visibilizar o meio-ambiente como uma vítima do conflito e os fatores que nos permitem dar dita conotação. Foi usado o método hermenêutico baseado na revisão da doutrina, jurisprudência e normas que reconhecem o meio-ambiente como um direito. É necessário que se aborde e se tenha em conta por toda a comunidade juridicamente organizada chamada Estado Colombiano, que o meio-ambiente deve ser como um direito autônomo que é necessário para a vida, e para o desenvolvimento de cada um dos direitos e garantias de que gozam os associados ao Estado de Direito hoje convencionalizado.

Palavras-chave: Conflito armado, deflorestação, meio ambiente, mineração ilegal, vítima.

\section{Perfil}

Estudiante de derecho X nivel, Universidad Tecnológica del Chocó Diego Luis Córdoba. Correo: timdsas@gmail.com.

\section{Perfil}

Estudiante de derecho X nivel, Universidad Tecnológica del Chocó Diego Luis Córdoba. Correo electrónico: Hamestenis@hotmail.com

\section{Perfil}

Docente de planta Facultad de Derecho Universidad Tecnológica del Chocó Diego Luis Córdoba, Magister en Derecho Administrativo de la

\section{Perfil}

Decano de la Facultad de Derecho de la Universidad Tecnológica del Chocó Diego Luis Córdoba, Magister en Derecho Administrativo.

Autor para correspondencia: timdsas@gmail.com

Edwin Samir Asprilla Panesso

Hames Yanier Lozano Urrego

Rafael Bechara Palacio Abogado y licenciado en educación

Ricardo Emiro Ledezma Abogado 


\section{Introducción}

El origen de todo conflicto radica en el desacuerdo, "el conflicto es inherente a la coexistencia social (Marques, 2013, p. 27 citado por Arboleda, 2014, p. 197). Surge de la divergencia, la contraposición de necesidades, la búsqueda de intereses particulares, la disputa de recursos de cualquier naturaleza, especialmente cuando estos son escasos y están personificados". El conflicto armado en Colombia no es una excepción, este se ha desarrollado por más de 50 años y ha gestado un enfrentamiento entre diferentes grupos ilegales o al margen de la Ley y el Estado.

Siendo el conflicto colombiano un tema ampliamente tratado por la literatura, estudiado y analizado, existen diferentes vertientes que tratan de dar una explicación del inicio del mismo, desde diferentes ópticas, políticas, sociales, culturales y económicas; podría afirmarse que una de las causas económicas más ampliamente defendidas es la existencia de la desigualdad social, del abandono de algunas zonas del país que aumentan la brecha entre la pobreza y la riqueza. Según el informe anual del Foro Económico de Davos "Colombia es el segundo país más desigual en la distribución del ingreso en la región. El 1 por ciento más rico de la población concentra el 20 por ciento del ingreso" ("En 2017 aumentó", 2017). Situación que no se aleja de la realidad mundial.

Otra parte de la literatura sostiene que el conflicto no se origina por la desigualdad sino por la codicia, por el deseo de algunos de apropiarse de los recursos,

Las raíces de los conflictos armados no se encuentran en los resentimientos y desigualdades socioeconómicas, como se creía, sino en los intereses económicos de algunos grupos en conflicto. Adicionalmente, en las sociedades preva- lentemente pobres se pueden reclutar fuerzas armadas irregulares a bajos costos; en consecuencia, los actores sociales desafían la autoridad estatal con el fin de apropiarse de los recursos "saqueables" (Yaffe, 2011, p.193).

Como factor político "para algunos analistas la "precariedad estatal" se centra en la necesidad de mejorar las capacidades militares y policivas, con el fin de ejercer una autoridad más efectiva en una sociedad propensa a la violencia. Para otros, esta precariedad se refiere a las debilidades de la democracia y del Estado de derecho en Colombia" dejando olvidadas algunas comunidades más proclives a la violencia por la no presencia estatal que aumento las posibilidades de formación de grupos armados al margen de la Ley, "la insuficiente presencia institucional, explicando que muchos países Latinoamericanos - entre ellos Colombia y Perú, por ejemplo-, han sido incapaces de controlar su territorio nacional, o de contrarrestar los efectos de las poderosas organizaciones de narcotráfico que operan en sus fronteras" (Yaffe, 2011, p.200).

El conflicto armado comienza con la Violencia. Y la Violencia está asociada a dos factores originarios que se influyen mutuamente: el control sobre la tierra y sobre el Estado, sobre todo a partir de la subida del precio del café, y los presupuestos de gastos de los gobiernos aumentan considerablemente (Molano, 2010, p.1).

El chocó ha sido el epicentro del conflicto en Colombia, puesto que a lo largo de su historia se ha permeado por la violencia y la desigualdad de una forma más notoria y prolongada,

La guerrilla apareció en el Urabá a finales de los 60 cuando las Farc expandieron sus frentes. Urabá fue terreno propició por cuanto allí llegaron colonos cercanos 
al Partido Comunista quienes habían avanzado en la organización política del campesinado. A principios de los 70, luego de la división internacional del bloque comunista, el EPL surge como la respuesta y apuesta armada del sector maoísta escindido del Partido Comunista. Bernardo Gutiérrez, comandante del $\vee$ Frente deserta junto con varios de sus hombres y armas y se integra al $E P L$, arrastrando consigo las redes y circuitos propios de la clandestinidad que permitirían al EPL ampliar su margen de acción de Córdoba al Urabá. En los años 80 , tras un replanteamiento político, el EPL se incrusta en el corazón del eje económico, social, y político con su inserción en los sindicatos y con las invasiones de tierra en zona rural y en los núcleos urbanos. Con lo anterior el conflicto guerrillero acaba condicionando la dinámica del conjunto de los conflictos sociales y el territorio se divide grosso modo entre norte -EPL- y el sur -Farc-. El eje bananero se convierte en eje de la disputa interguerrillera (Espinosa, 2012, p. 296).

Según el informe departamental de hechos victimizantes al año 2012 se evidencia que:

"el número de víctimas, por año, que rindieron declaración en alguno de los municipios del departamento de Chocó. El comportamiento de la serie refleja una tendencia creciente que se inicia en el año 1.997 y alcanza un máximo histórico en el 2.002, año en el que se registran 25.672 personas declarantes. Durante el periodo 2.003-2.006 se observa un comportamiento decreciente que se invierte durante el año 2.007y se mantiene para el periodo 2.010-2.011" (Unidad para la atención y reparación integral a las víctimas, 2012) delitos que oscilan entre homicidios, tortura, desaparecimiento forzado, delitos contra la libertad sexual y la integri- dad sexual, lesiones personales (con incapacidades permanentes), sin dejar de desconocer que el número es mucho mayor, dado que solo se puede contabilizar los hechos denunciados, sin tener en cuenta los que se dejan en el silencio.

Así mismo el medio ambiente es una víctima del conflicto pero de manera silenciosa, ya que los daños al entorno son usados como medio de presión para el Estado, es cotidiano que noticias como las emitidas por El Colombiano, "El medio ambiente: otra víctima silenciosa del conflicto" (2015) por el derrame de petróleo en las cuencas hídricas del choco, la instalación de minas antipersona, la siembra de cultivos ilícitos, minería ilegal entre otros son usados como "métodos de guerra", creando la necesidad de decretar emergencias ambientales como la decretada en el Putumayo en el año 2015 por el derrame de 23 tanques de Petroleo ("Farc ocasionaron emergencia", 2015).

Adicional a ello es conocido incluso en el ámbito internacional el despilfarro por parte de las organizaciones a margen de la Ley de los recursos naturales del país:

Después de Brasil, Colombia es el segundo país en el mundo en el ránking de biodiversidad y a nivel de aves y de orquídeas el número uno. Más de 56.000 especies (con alrededor de 1.200 especies en distintas categorías de amenaza) habitan el territorio nacional y anualmente se incautan miles de animales en diferentes partes del país, animales que provienen principalmente de los departamentos del Caquetá, Chocó, Arauca Putumayo, según Global biodiversity information facility (Manfred, 2016).

Por lo anterior por medio de este artículo se pretende dilucidar desde diferentes ópticas el impacto del conflicto en el medio ambiente, 
principalmente en el departamento del Cho$\mathrm{co}, \mathrm{y}$ las posibles consecuencias que trae para el país para el mundo, el maltrato del entorno.

\section{Medio ambiente}

Es una expresión que a todas luces de nota muchos significados, para el Banco de la República "es el análisis de la relación entre ecosistema y cultura en general, es el entorno en el cual opera una organización, que incluye el aire, el agua, el suelo, los recursos naturales, la flora, la fauna, los seres humanos, y su interrelación" (Subgerencia Cultural del Banco de la República, 2015).

Según Vincenti (s.f.), es un sistema de relaciones muy complejas (entre la atmósfera, la hidrósfera, la litósfera, la biósfera y la gnósfera), con gran sensibilidad a la variación de uno sólo de sus factores, que al modificarse provocan reacciones en cadena"

Para la UNESCO (1989), el medio ambiente es todo aquello que rodea al ser humano y que comprende elementos naturales, tanto físico, como biológicos; elementos artificiales (la tecno estructura); elementos sociales, y la relación de todos estos elementos entre sí.

Para lo que nos atañe es importante resaltar que el ser humano hace parte del medio ambiente, tal cual como lo manifiesta, la declaración de la Conferencia De Las Naciones Unidas sobre el medio humano, cuando expresa, el hombre es a la vez obra y artífice del medio ambiente que lo rodea, el cual le da el sustento material y le brinda la oportunidad de desarrollarse intelectual, moral social y espiritualmente (ONU, 1972).

Para hablar de medio ambiente es imperativo hablar de desarrollo sostenible entendido como aquel desarrollo económico que no pone en riesgo a las generaciones futuras, sin embargo a lo largo del tiempo el ser humano ha venido realizando múltiples actividades que han afectado de una u otra forma a su entorno incluyendo en este a otros seres humanos, una de esas actividades es la llamamos guerra, según el principio 24 Declaración de Rio La guerra es, por definición, enemiga del desarrollo sostenible. En consecuencia, los Estados deberán respetar las disposiciones de derecho internacional que protegen al medio ambiente en épocas de conflicto armado, y cooperar en su ulterior desarrollo, según sea necesario (ONU, 1992).

\section{VICTIMAS}

Existen muchas definiciones sobre este tema dada la importancia, puede entenderse como víctima de manera general, a todo sujeto que sufre daño o afectaciones, ocasionadas por el accionar de otro sujeto, el primero denominado sujeto pasivo y el segundo sujeto activo.

La Corte Constitucional en sentencia C-052 del 2012 MP. Nilson Pinilla Pinilla. Manifiesta que, se reconoce como víctimas a todas las personas que hubieren sufrido un daño, como consecuencia de los hechos que el mismo precepto determina a continuación. Así, pese a que existen también otros criterios relevantes, el concepto de daño es el más significativo de todos, pues es de la acreditación de su ocurrencia que depende que las personas interesadas logren ser reconocidas como víctimas y accedan a los importantes beneficios establecidos en esta normativa

De otro lado, a la luz del artículo 3 de la Ley 1448 del 2011 se consideran víctimas, aquellas personas que individual o colectivamente hayan sufrido un daño por hechos ocurridos a partir del 1 de enero de 1985, como consecuencia de infracciones al Derecho Internacional Huma- 
nitario o de violaciones graves y manifiestas a las normas internacionales de Derechos Humanos, ocurridas con ocasión del conflicto armado interno.

Es claro que para hablar de victima debe configurarse un elemento esencial ya mencionado como lo es el daño o afectación, según Decreto-Ley 4635 de 2011 en su Artículo 9. Daño ambiental y territorial. Se produce un daño ambiental y territorial cuando por razón de los hechos victimizantes a que se refiere el artículo $3^{\circ}$ de este decreto, se afectan los ecosistemas naturales, la sostenibilidad y sustentabilidad del territorio de las comunidades. La restauración del entorno natural y la adopción de medidas para su protección serán condiciones básicas para garantizar la salvaguarda de la relación indisoluble entre territorio, naturaleza e identidad cultural.

Según la Red nacional de información (2017) a corte 1 de octubre de 2017 existen 8.227.623 víctimas del conflicto armado en Colombia.

\section{CONFLICTO ARMADO}

Un conflicto armado es aquella confrontación en la cual está inmersa el uso de las armas, en ese sentido, EI DIH hace una distinción entre dos tipos de conflictos armados, a saber: Conflictos armados internacionales, en que se enfrentan dos o más Estados, y conflictos armados no internacionales, entre fuerzas gubernamentales y grupos armados no gubernamentales, o entre esos grupos únicamente (CICR, 2008):

\section{En el mundo}

Siria: Como sabes, desde 2011 este país se encuentra sumido en un enfrentamiento continuo. Casi cada día los medios de comunicación de nuestro país se hacen eco de las situaciones allí vividas. La guerra ha dejado decenas de miles de muertos, muchos de ellos civiles, y millones de desplazados que lo abandonan todo para buscar una nueva vida.

Afganistán: Estalló en 2001 y se calcula que desde entonces han muerto más de 200.000 personas, entre las que se incluyen civiles.

Pakistán: El norte del país se encuentra actualmente en conflicto entre el Gobierno y algunos grupos armados. Más de dos millones de personas han tenido que dejar sus casas en esta zona del país para encontrar un nuevo hogar lejos de los disturbios.

República Centroafricana: Esta guerra ha provocado más de un millón de desplazamientos, afectando gravemente a su sociedad y a su economía. Casi el $70 \%$ de los niños han tenido que abandonar la escuela para buscar un sitio más seguro, dejando de lado sus derechos fundamentales.

Sudán del Sur: A causa de la guerra, su población vive una importante crisis alimentaria. Además, se calcula que solo el 15 \% del país tiene acceso a medidas básicas de higiene. Yuba es la capital de uno de los países más jóvenes del mundo.

Somalia: El conflicto que se desarrolla en este país estalló en 1991 y desde entonces ha dejado más de 400.000 muertos y más de un millón de somalíes han huido a países vecinos.

República Democrática del Congo: En este caso, el número de desplazados supera los 2.700.000. Se han habilitado más de 30 campos de refugiados para atender las demandas de la población afectada por los enfrentamientos.

Nigeria: Desde 2004, entre 4.000 y 5.000 personas han perdido la vida, y cientos de niñas fueron secuestradas a causa del conflicto. 


\section{En Colombia}

El origen de todo conflicto radica en el desacuerdo, y el conflicto armado en Colombia no es una excepción, este se ha desarrollado por más de 50 años y ha gestado un enfrentamiento entre diferentes grupos ilegales o al margen de la Ley y el Estado. Tal como lo manifiesta la Comisión Histórica del Conflicto y sus Víctima. (2015). "En la fase inicial del conflicto armado en Colombia, cuyas dimensiones eran muy reducidas -si acaso un conflicto de muy baja intensidad-, la confrontación tuvo dos actores fundamentales: por una parte, las "guerrillas de primera generación" y las Fuerzas Militares" (p.49). Aunque pudo haberse originado por muchos factores, su origen puede estar ligado a un desacuerdo por la tierra o parte agraria. Postura que veo compartida por algunos de los expertos que entregaron un informe para entender el origen del conflicto y que integran la comisión histórica del conflicto y sus víctimas.

\section{En el Chocó}

El departamento del Choco es considerado unos de los lugares más biodiversos del planeta, aproximadamente el $25 \%$ de las especies que pueden hallarse allí no se encuentran en otro lugar del mundo por lo que hace de este un sitio privilegiado para el turismo ecológico.

Chocó Biogeográfico es un corredor natural neotropical que inicia sus límites de norte a sur así: desde la provincia de Darién al este de Panamá, cruzando por todo el occidente Colombiano hasta el noroeste del Ecuador y termina en el extremo norte del Perú. Y en sentido occidente a oriente, comprende desde, la Costa Pacífica hasta la cordillera occidental, lo que significa que este corredor cruza por el litoral pacífico de cua- tro países y en algunos se adentra hasta valles, vertientes o incluso hasta el litoral caribe.

El Urabá chocoano o Bajo Atrato es una región estratégica para los actores armados por ser un corredor que facilita la entrada de armas y la salida de droga procesada. En esta medida, la situación de las comunidades negras e indígenas (Emberá Katíos principalmente), así como de colonos venidos de los departamentos de Córdoba y Urabá, se vio afectada desde mediados de los años noventa.

Aproximadamente el 6,3 \% de El Chocó es protegido por Reservas Ecológicas y Parques Nacionales. Hay esfuerzos en curso para conectar estas áreas protegidas y formar un pasillo continuo de la conservación que se extienda de Panamá a Perú. Muchas organizaciones están también trabajando para fortalecer la protección de los Parques y Reservas existentes para asegurar su futura conservación (Botero, 2010).

En 1996, la acción paramilitar combinada con la de las fuerzas armadas, logra un repliegue importante de la guerrilla del Urabá antioqueño. Las acciones prosiguen hacia la parte chocoana de Urabá y el Bajo Atrato, extendiéndose luego hasta el Medio Atrato. En el marco de esta ofensiva contrainsurgente se va a producir entre diciembre de 1996 y febrero de 1997, el desplazamiento forzado de aproximadamente 15.000 personas en el área del Bajo Atrato (Agudelo, 2001).

Las acciones de las fuerzas militares van desde restricción en las vías de acceso, de alimentos o del desplazamiento de personas, hasta homicidios o desaparición forzada de una gran cantidad de personas.

En el Chocó los procesos de corrupción se han convertido en una constante 
desde la creación misma del departamento en la década de 1940. El establecimiento en el departamento de clanes familiares, que han dominado el espectro político, realizando capturas institucional y de rentas por medio del nepotismo ha generado un monopolio de la administración pública en pocas manos. Este fenómeno aunado al abandono del Estado en términos de asistencia social, no sólo en expresiones de educación, donde la cobertura es de las más bajas en el país, sino igualmente en salud y sobre todo en desarrollo sostenible, muestran al Chocó como uno de los departamentos más pobres de Colombia. Asimismo, la única fuente de empleo legal en la mayoría de los municipios es la pública, o bien las Alcaldías o la Gobernación. Las vías en mal estado y la inexistencia de la empresa privada en sectores urbanos profundizan dicho problema (López, s.f).

La presencia de grupos armados al margen de la Ley y la búsqueda de la recuperación del territorio por parte del Estado han ocasionado que el Choco tenga un gran número de civiles víctimas del conflicto armado, situación que agudiza la brecha social de esta comunidad con respecto al resto del país, viéndose enfrentado a constantes luchas por el territorio, generando un número significativo de desplazamientos forzados que ocasionan la perdida cultural y de identidad significativa. En la figura 1 se muestra la presencia de estos grupos en el departamento.

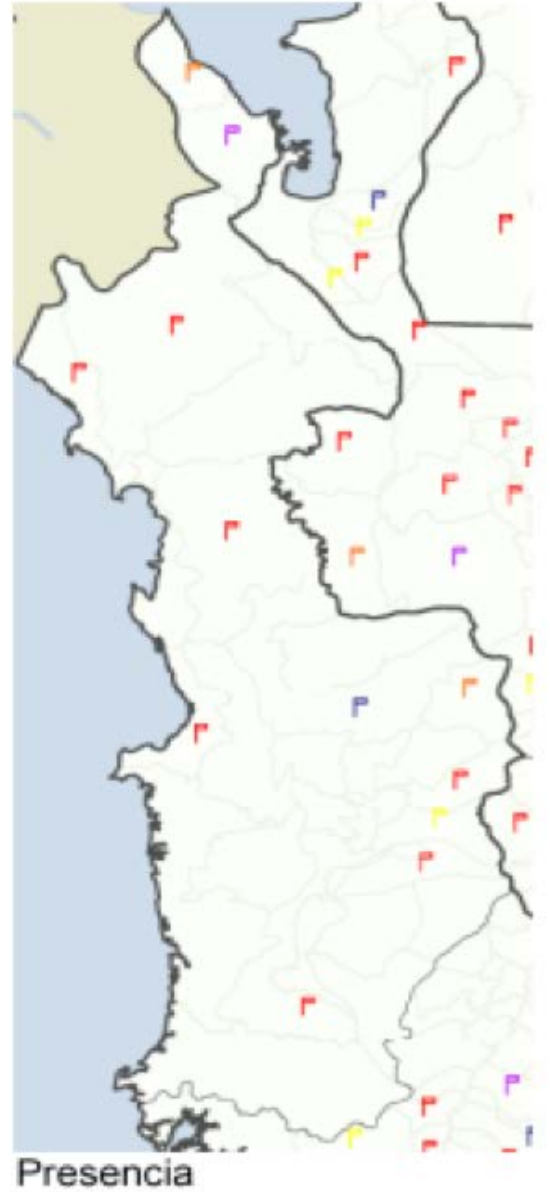

\section{Guerrilla \\ Disputa prevalencia guerrilla Paramilitares \\ Disputa prevalencia paramilitares Disputa \\ Sin registro de presencia violenta}

Figura 1. Presencia conflicto Choco 1997-2001 Fuente: (López, s.f).

Las poblaciones indígenasy sus comunidades, así como otras comunidades locales, desempeñan un papel fundamental en la ordenación del medio ambiente y en el desarrollo debido a sus conocimientos y prácticas tradicionales. Los Estados deberían reconocer y apoyar debidamente su identidad, cultura e intereses y hacer posible su participación efectiva en el logro del desarrollo sostenible (ONU, 1972). 


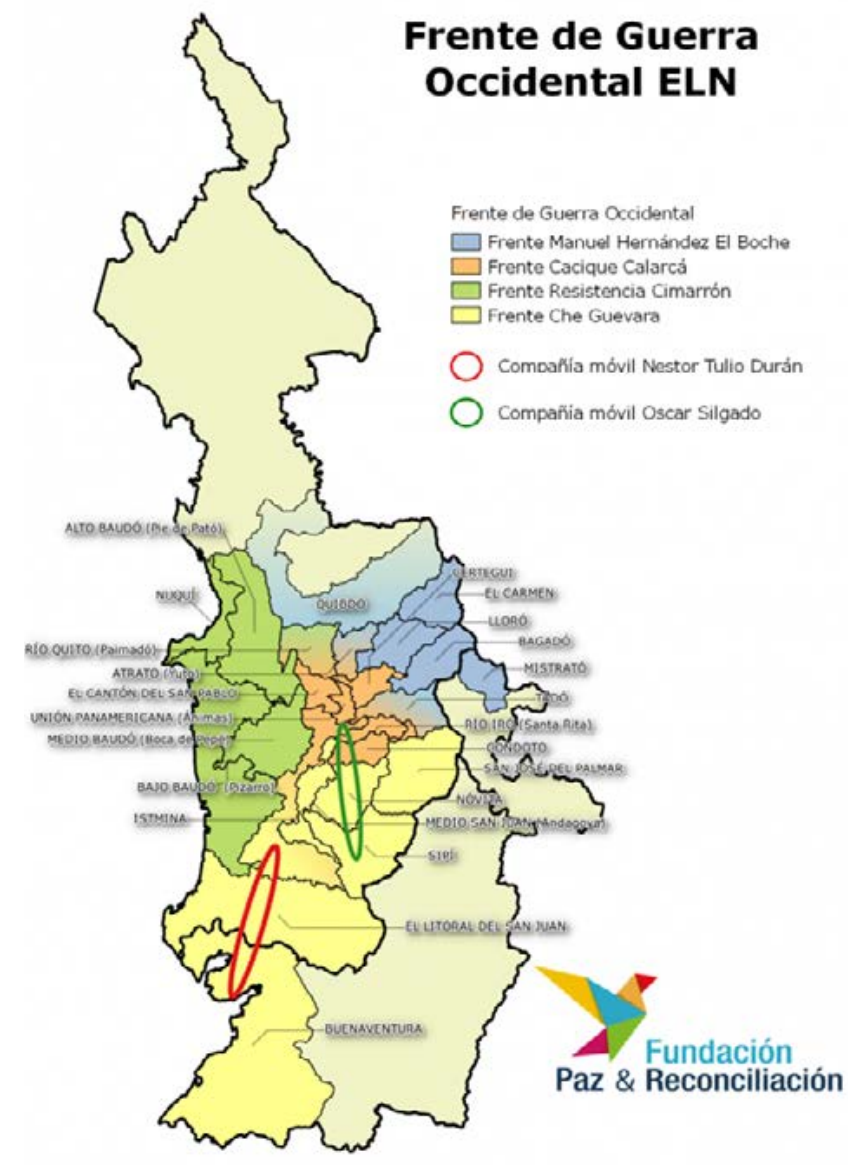

Figura 2. Mapa de la guerra en el Choco Fuente: (Fundación Paz \& Reconciliación, 2017).

\section{Efectos del conflicto armado}

Este acápite lo entenderemos como aquellas consecuencias que ha dejado el conflicto armado, lo vamos a mirar desde dos puntos de vistas, 1 en cuanto a las personas y 2 en cuanto al medio ambiente.

\section{En cuanto a las personas}

Según el Registro Único de Víctimas, el Chocó es el sexto departamento más afectado por el conflicto armado, con 382.646 víctimas entre 1985 y el 1 de septiembre 2014 (Registro Único de Víctimas, 2017).

\section{Líderes sociales asesinados en Colombia en 2017}

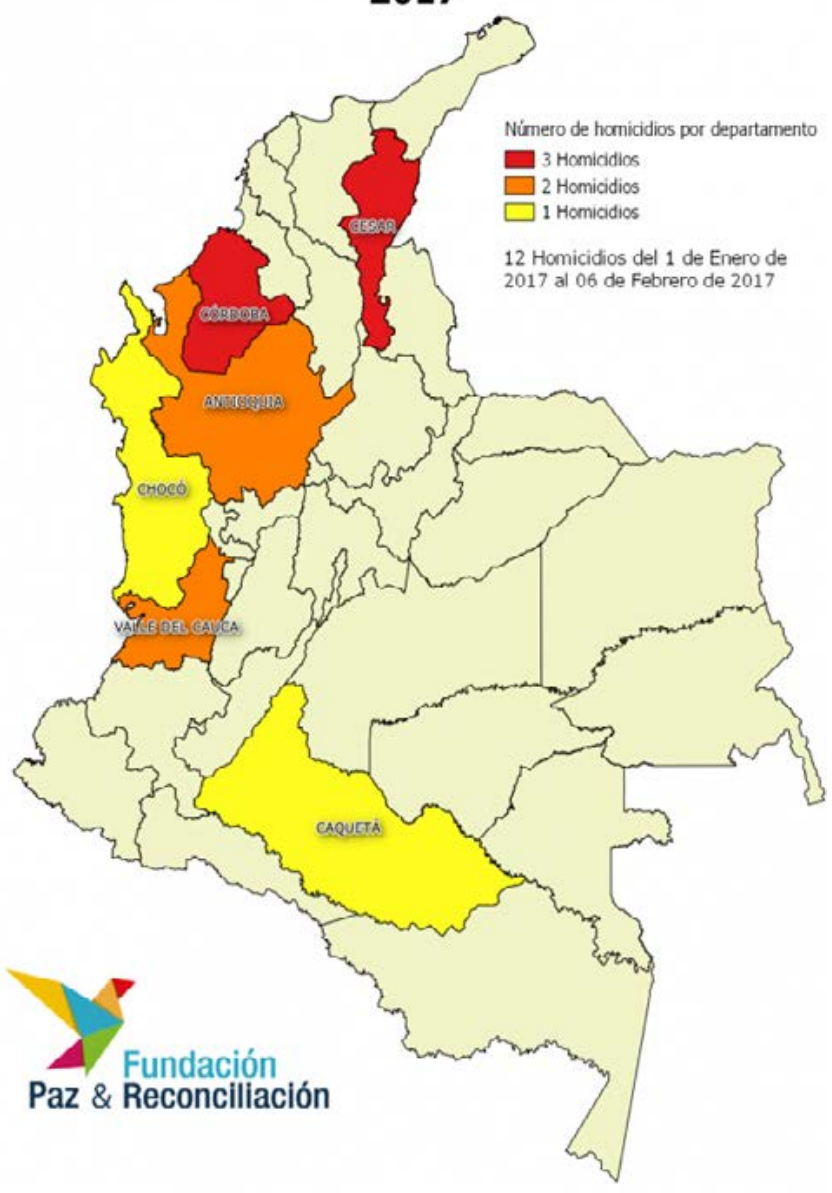

Figura 3. Líderes sociales asesinados en el 2017 Fuente: (Fundación Paz\& Reconciliación, 2017).

Uno de los efectos del conflicto armado es que muchas familias salen de sus tierras huyendo de la violencia bien sea por enfrentamientos entre grupos o por amenazas contra su vida manifestadas por los mismos, según Darío Fajardo (2015) La convergencia del desarrollo de la agricultura de plantaciones con el conflicto armado ha conducido a extendidos procesos de expropiación y destierro de pequeños y aún medianos propietarios. Después de que estas personas son despojadas de sus tierras los grupos al margen de la Ley las utilizan para el sembrado de cocaína, es uno de los motores de la deforestación. 
La población del Chocó ha sido impactada por asesinatos selectivos y masacres, reclutamiento de menores, uso de minas antipersonal (MAP) y artefactos explosivos improvisados (AEI), desplazamiento masivo, confinamiento, y explotación de cultivos de uso ilícito, de la minería informal por grupos armados no estatales y para estatales, entre otros. Pero el impacto más arrollador ha sido el desplazamiento. Según el Departamento de Prosperidad Social, actualmente, la mitad de la población del Chocó persiste en situación de desplazamiento, con 279.507 víctimas de este fenómeno entre el año 1985 y el 2013, provenientes principalmente del Medio Baudó y el Medio Atrato, corresponden al 5,6 por ciento de las personas desplazadas del país (Serra-Horguelin \& Schoeller, 2014, p. 7).

Así mismo el uso de los menores para el conflicto armado, la instalación y detonación de minas antipersona, el asesinato de líderes comunitarios, el secuestro y la extorción, la sensación de falta de apoyo estatal hace que se des contextualice la estatalidad de las entidades y se cree una desdibujada imagen de la norma que rige si la estatal o la insurgente, afianzando como consecuencia la brecha de la violencia y la desigualdad.

\section{En cuanto al medio ambiente}

Este conflicto, que ha dejado miles de personas heridas, asesinadas y poblaciones desplazadas, también ha dejado otra víctima como lo es el medio ambiente. Esta víctima del conflicto armado colombiano, en especial en el departamento del Chocó, ha sufrido múltiples afectaciones, por ejemplo; la deforestación causada por los grupos ilegales para poder sembrar cultivos ilícitos, ò al momento de establecer sus campamentos, que además, genera la pérdida del hábitat de la fauna del lugar, de otro lado, la contaminación del aire por los químicos provenientes de los laboratorios que utilizan para la producción de sustancias psicotrópicas, otra afectación es la contaminación de las fuentes hídricas derivadas de la explotación minera con mercurio, que genera afectación a la fauna acuática y a la salud de las personas, toda vez, que muchos utilizan esa agua contaminada para realizar múltiples actividades, bañarse, cocinar entre otras.

Podemos observar de manera contundente que estos efectos del conflicto armado vulneran el derecho constitucional que tenemos todos los colombianos a gozar de un ambiente sano. Artículo 79 de la Constitución Política de Colombia. Este derecho también está consagrado en el artículo 11 \#1 del Protocolo De San Salvador. Colocando en riesgo a las generaciones futuras afectando de manera tajante el concepto de desarrollo sostenible a que se refiere el artículo 3 de la Ley 99 del 93. Donde reza, Se entiende por desarrollo sostenible el que conduzca al desarrollo económico, a la elevación de la calidad de vida y al bienestar social, sin agotar la base de recursos naturales renovables en que se sustenta, ni deteriorar el medio ambiente o el derecho de las generaciones futuras a utilizarlo para la satisfacción de sus propias necesidades.

La directora del Instituto Humboldt Brigitte Baptiste explicó que, "además de víctima, el ambiente fue parte del conflicto por la distribución y acceso inequitativos a los beneficios que ofrece la biodiversidad: "el derecho y la cualidad de controlar procesos ecosistémicos y de disputar la gobernabilidad de los territorios fue un elemento central en la historia del conflicto desde el punto de vista ambiental" (Instituto Humboldt, 2017).

Los Estados deben cooperar para continuar desarrollando el derecho internacional en lo que se refiere a la responsabilidad y a la indemnización a las víctimas de la contaminación y otros daños ambientales que las acti- 
vidades realizadas dentro de la jurisdicción o bajo el control de tales Estados causen a zonas situadas fuera de su jurisdicción (ONU, 1972).

\section{Minería ilegal}

El departamento del choco es unos de los más ricos en minerales como el oro y el platino, todo esto debido a su posición geográfica, a su composición hidrográfica y la naturaleza de sus terrenos.

En general las minas del Chocó y de Barbacoas son consideradas como las más ricas. En la Provincia del Chocó el suelo es, por decirlo así, enteramente de oro. No sólo posee en su superficie las más ricas maderas, se sacan también de su suelo los tesoros más preciosos y más abundantes; por todas partes donde se cava, entre ciento y ochocientas varas de altura, se encuentra oro (Restrepo, 1988).

Una misión del Programa de las Naciones Unidas para el Medio Ambiente (ONU Medio Ambiente) visitó distintas áreas degradadas por el conflicto armado en los departamentos de Chocó y Antioquia. Allí identificó aspectos puntuales en los que se deben concentrar las acciones para la gestión sostenible de los recursos y la conservación del medioambiente en el posconflicto.

De continuar esta actividad sin una estrategia integral, puede llegar a ponerse en riesgo la paz en esos territorios, porque esta actividad ilícita es muy fácil de ser cooptada por grupos al margen de la ley y nuevos actores de la guerra ("El medio ambiente", 2017).

Esta realidad es tan preocupante, que en un estudio efectuado por el DNP se menciona que Colombia es el tercer país que más libera mercurio en el mundo con 75 toneladas anuales, ubicándose detrás de China e Indonesia. Lo anterior a causa principalmente de la mine- ría de oro artesanal y de pequeña escala. De igual manera, se indica que el $86 \%$ de la minería en el país se realiza sin título minero y sin licencia ambiental, lo que genera graves problemas sociales y una gran tragedia ambiental que, además, según el Instituto Nacional de Salud, ha generado 1.126 casos de intoxicación (Rodríguez, 2016).

\section{Deforestación}

Para nadie es un secreto que la deforestación en el departamento del Chocó como en muchos otros departamentos, está muy asociada con el conflicto armado, ya que se talan hectáreas de bosques para dedicarlas al cultivo de coca, dejando de esta forma a muchas especies sin habita y afectando el suelo por el monocultivo.

"El $58 \%$ de la deforestación en Colombia ha ocurrido en municipios de conflicto. En los últimos 25 años en Colombia se han deforestado 5 millones de hectáreas, de las cuales 3 millones están en municipios de conflicto armado", señaló Simón Gaviria, director del DNP. Al parecer, el cultivo de coca es uno de los factores que más ha contribuido a que se disparen las cifras de tala. Se calcula que por cada hectárea que se siembre de aquella planta, se deben deforestar 1,7 hectáreas de bosque. $Y$ anualmente, como lo muestra el DNP, se siembran unas 74.687 ha de coca en Colombia (Redacción Vivir, 2015).

Aunque los cultivos de coca no son la principal causa de deforestación en Colombia, estos han generado impactos en los ecosistemas, afectando la biodiversidad en áreas de gran importancia ambiental. Según la metodología de la Oficina de las Naciones Unidas contra la Droga y el Delito - UNODC5, la interpretación de imágenes de satélite indica que los cultivos de uso ilícito (coca) en Colombia se localizan en 24 de los 32 departa- 
mentos del país entre los que se encuentra el departamento del choco (Bello, Báez, Gómez, Orrego \& Nägele, 2014, p. 214).

De acuerdo con la última actualización de cifras de monitoreo de bosques, los principales motores de la deforestación en Colombia son praderización 45 \%; cultivos de uso ilícito, 22 \%; desarrollo de infraestructura vial, $10 \%$; incendios forestales, $8 \%$; ganadería extensiva, 8\% extracción ilícita de minerales, 7 \%.

Durante el 2016 la deforestación se concentró en siete núcleos identificados en el país: Arco de deforestación de la Amazonia con un 34\%; Pacífico Norte, $14 \%$; Nororiente de Antioquia, $8 \%$; Norte de Santander, $8 \%$; Pacífico Sur, 2\%; Sur del Chocó, $1 \%$ y Sarare, $1 \%$ de la deforestación observada (Ideam, 2017)

Para el 2016 las zonas más críticas en cuanto a deforestación de las 7 enunciadas hay 2 en el choco Sur del Chocó: en los municipios de Río Quito, El Cantón de San Pablo, Atrato, Cértegui y Unión Panamericana se reporta el $1 \%$ de la deforestación observada, y en el Pacífico norte: en el área del noroccidente antioqueño y el norte de Chocó se concentró el 14 \% de la deforestación reportada. Las áreas afectadas son principalmente los municipios de Turbo (Antioquia); Riosucio y Unguía (Chocó) ("Así depredan los bosques", 2017).

\section{Medio ambiente como sujeto de derechos}

Existen algunos países en Suramérica como ecuador y Bolivia los cuales reconocen a la pacha mama como sujeto de derechos debido a su importancia, en Colombia, aunque la Constitución Política expresamente no lo contempla, si establece algunos artículos para la protección del medio ambiente. Este tema está tomando mucha relevancia, toda vez que el medio ambiente ha venido sufriendo múltiples afectaciones por diferentes factores, bien sea por la deforestación, la contaminación por residuos sólidos de las fuentes hídricas y uno muy importante la contaminación de la fuentes hídricas con mercurio producido por la minería, este factor generó un pronunciamiento de la corte constitucional con la sentencia $T$ 622 de 2016 la cual reconoce al rio Atrato uno de los más importantes del departamento del Chocó cono sujeto de derechos.

\section{El Medio Ambiente y su Protección en el Sis- tema Interamericano de Derecho Humanos}

Si bien en el sistema interamericano de protección de derechos humanos, y el universal no existe un compendio o un corpus iuris que determine o defina de manera expresa el medio ambiente como un derecho humano autónomo, o independiente ya que la protección que se le da a este es a través de los individuos de la especie humana o personas, si debemos decir que existen instrumentos itos en materia de protección a los derechos humanos y al derecho internacional humanitario que han hecho referencia a nuestro entorno natural, lo mismo ha hecho la jurisprudencia de Órganos Supra Constitucionales, Cortes Internas y el la doctrina internacional, una referencia es la Declaración Universidad de Derechos Humanos que data de 1948 en donde una de las ideas primarias era ofrecerle al hombre una tierra llena de libertades pero también de garantías que le permitieran gozar de un medio propicio para el desarrollo de cada uno de sus derechos y libertades. Paralelo a ello ya en 1972 se desarrolla la Convención de Estocolmo, de donde se resaltan los principios que, aunque de manera enunciativa proclamaban la importancia y necesidad de que los Estados del Planeta tierra adoptaran medidas para proteger la especie humana y su medio ambiente como componente que condicionaba su existir., nuestro Estado Colombiano sin ser ajeno a dicha realidad adopto dicho principios y los introdujo a nuestro canon constitucional dándole la rele- 
vancia y categoría de derechos fundamental constitucional al medio ambiente fundamentos que se cimentan en el artículo 79 constitucional entre otras disposiciones normativas entre las que resaltamos: La Ley 23 de 1973, mediante la cual Colombia adoptó el sistema regulatorio para la prevención y control de la contaminación. Así se inicia a gestar la legislación ambiental nacional, regulando aspectos como niveles de contaminación y manejo de residuos. subsiguientemente el Gobierno Nacional, mediante Decreto 2811 de diciembre 8 de 1974, expidió el Código de los Recursos Naturales Renovables y de Protección al Ambiente, el cual se alza como la primera norma ambiental que regula el manejo de los recursos no renovables cinco años más tarde se estableció la Ley 9 de 1979 sobre medidas sanitarias y el Capítulo II del Título VI -Parte III- Libro II y el Título III de la Parte II -Libro I- del Decreto 2811 de 1974 (Código de los Recursos Naturales Renovables y de Protección al Ambiente), en cuanto a usos del agua y residuos líquidos; Seguido de esto se introdujo el Decreto 1594 de 1984 tratante de la anterior, en 1991 se refundó el Estado colombiano cimentándose en la denominada constitución ecológica, que por su contenido proteccionista del medio ambiente fue objeto de constantes enaltecimientos por los doctrinantes, pero era necesario darle desarrollo a los postulados establecidos en la constitución, por eso se creó la Ley 99 de 1993 Como desarrollo de principios y derechos contenidos en la Constitución Nacional de 1991, respuesta al compromiso internacional adquirido en la Declaración de Río en 1992 y ante la gravedad de la situación medio-ambiental, el Congreso Nacional de Colombia expidió la Ley 99 de por la cual se crea el Ministerio del Medio Ambiente, se reordena el sector público encargado de la gestión y conservación del medio ambiente y los recursos naturales renovables, se organiza el Sistema Nacional Ambiental, SINA, y se dictan otras disposiciones, estos antecedente conforman la base sustantiva del derecho ambiental en Colombia.

La década de los 90 es de gran importancia para el derecho ambiental pues la comunidad internacional materializa esfuerzos para la tutela del medio ambiente, así el 9 de mayo de 1992 en New York se adoptó la convención marco de las naciones unidas sobre el cambio climático reconoce la preocupación global por las actividades humanas que han modificado las concentraciones naturales de gases de efecto invernadero en la atmósfera, intensificando así el efecto invernadero natural estos cambios implicarían un aumento en la temperatura de la superficie y la atmósfera de la Tierra que pueden acarrear efectos negativos sobre los ecosistemas y la humanidad el objetivo principal de la Convención es lograr la estabilización de las concentraciones de gases de efecto invernadero en la atmósfera a un nivel que impida interferencias peligrosas de las actividades humanas en el sistema climático.

Meses después se gestaría la cumbre de la tierra en rio 92 dando así vida a normatividad que se regiría como piedra angular del derecho ambiental, como lo fueron; la declaración de rio de janeiro del 16 de junio la cual se concibe Como un conjunto de principios sin fuerza jurídicamente vinculante, la Declaración busca reafirmar y desarrollar la ONU (1972). Esto con el principal objetivo de alcanzar el desarrollo sostenible, reconociendo el derecho de los seres humanos a una vida saludable y productiva en armonía con la naturaleza, así como el derecho soberano de los Estados para aprovechar sus recursos naturales y haciendo explícita la responsabilidad de los mismos de velar por la conservación del medio ambiente, en el sentido de evitar que las actividades que se realizan bajo su jurisdicción o control causen daño al medio ambiente de otros Estados o en áreas fuera de cualquier jurisdicción nacional En el marco de este objetivo, la Declaración contempla acciones que se deberían adoptar 
en el ámbito social, económico, cultural, científico, institucional, legal y político también se gestó la el convenio sobre la diversidad biológica el 5 de junio del mismo año, Tomando como punto de partida el reconocimiento de la importancia de la diversidad biológica para la evolución y la vida de la biosfera, así como sus valores ecológicos, económicos, científicos, entre otros y del hecho de que la pérdida de la biodiversidad ha sido el resultado de ciertas actividades humanas (Preámbulo), el Convenio Sobre la Diversidad Biológica tiene tres objetivos generales: la conservación de la diversidad biológica, la utilización sostenible de sus componentes y la participación justa y equitativa en los beneficios que se deriven de la utilización de los recursos genéticos, mediante, entre otras cosas, un acceso adecuado a esos recursos, una transferencia apropiada de las tecnologías pertinentes y una financiación apropiada.

Después de la convención de Río, todos los tratados económicos importantes comenzaron a incluir la protección del medio ambiente. La Convención sobre el Cambio Climático merece mención especial ya que, desde 1995, sus firmantes se han reunido cada año en la llamada Conferencia de las Partes (COP). En ese marco, en 1997, se presentó el Protocolo de Kioto que fue el primer acuerdo internacional en establecer obligaciones jurídicamente vinculantes para los países desarrollados, en el 2000, 189 países reunidos en Nueva York adoptaron la Declaración del Milenio, misma que fortaleció la importancia del desarrollo sostenible al reconocer la necesidad de un crecimiento económico sostenible con un enfoque en los pobres y el respeto a los derechos humanos dos años más tarde, en 2002, representantes de 190 países acudieron a la Cumbre Mundial de la ONU sobre el Desarrollo Sostenible, en Johannesburgo, para dar seguimiento a los compromisos de la Cumbre de Río. En esa ocasión, adoptaron la Declaración sobre el Desarrollo Sostenible, centrada en el desarrollo y la erradicación de la pobreza con un enfoque jurídico-económico sobre las "asociaciones público-privadas" Y en 2012, la ONU organizó la tercera Conferencia sobre el Desarrollo Sostenible, conocida como Río + 20, la cual convocó a 192 Estados miembros, empresas del sector privado, ONG y otras organizaciones. El resultado fue un documento El Futuro que Queremos. En las 49 páginas del documento, los Estados renuevan su compromiso al desarrollo sostenible y a la promoción de un futuro sustentable el cual es el esfuerzo de la comunidad internacional más reciente en pro de la tutela del medio ambiente.

No podemos dejar del lado que los tratados de ginebra de 1949, 1969 junto con sus protocolos adicionales I y II, también aunaron grandes esfuerzos para proteger nuestro ambiente sano, lo anterior porque determinaron bases para los procesos de humanización de las guerras, control en la utilización de las armas bélicas y/o químicas que al impactar causante graves afectaciones a la salud humana y deterioro al medio ambiente.

Sin embargo, estos instrumentos que han propendido por la diversidad e integridad de nuestro entorno natural, han sido tomados como afirma Manuel de Jesús Conrado Paz, de manera pávida ya que con la necesidad de sub desarrollo atienden cuestiones de represión a sus Estados vecinos ponen en una balanza entre la protección al medio ambiente y su cuestión desarrollo como potencias del mundo y entrar a un grupo que se puede distinguirse con la letra $G$, y terminan es por la necesidad de desarrollarse dejando a nuestro entorno en segundo plano.

Deber del Estado Colombiano de Reparar al Medio Ambiente como víctima en el Marco de la Justicia Transicional. 
En el momento histórico que vive el Estado Colombiano, por su transición del conflicto armado sin precedentes en el mundo por su duración por más de 60 años, extensión golpeo todos los sectores de la sociedad y por su degradación en el tiempo. Por lo anterior y teniendo en cuenta que la madre naturaleza es sujeto de derecho en tal sentido víctima del conflicto armado colombiano ya sea por acción o por omisión se ha permitido que la misma sufriera y sigue padeciendo en carne propia constantes afectaciones, en tal sentido en el rubro presupuestal nacional con apoyo o cooperación, inspección y vigilancia de organizaciones internacionales destinar a la reaparición al medio ambiente como víctima con miras a establecer políticas públicas efectivas de prevención, conservación, mantenimiento y restauración del ecosistema colombiano, para asegurar la diversidad e integridad de los mismos bajo los principios justicia, equidad y desarrollo sostenible.

\section{Responsabilidad}

El deber del Estado Colombiano de reparar al medio ambiente como víctima del conflicto armado interno, se sustenta en el artículo 90 de la Constitución Política Colombiana el cual obliga al Estado a responder patrimonialmente por los daños antijurídicos que le sean imputables, causados por la acción o la omisión de las autoridades públicas; y que el evento de ser condenado el Estado a la reparación patrimonial de uno de tales daños, que haya sido consecuencia de la conducta dolosa o gravemente culposa de un agente suyo, aquél deberá repetir contra éste, esto último es lo que conocemos como ACCION DE REPETICION.

La responsabilidad antes descrita se explica porque en muchos casos con conflicto armado que ha padecido el Estado Colombiano las autoridades han conocido de su posible ocurrencia y no han hecho nada, un caso emble- mático fueron las constantes denuncias que realizo la Diócesis de Quibdó, sobre la presencia de diversos grupos armados en las zonas del bajo Atrato y las autoridades competentes nunca hicieron nada para evitar dichos enfrentamientos dejando al azar la ocurrencia de la masacre de Bojayá y la de la cuenca del rio Cacarica, donde como se explicó con anterioridad el medio ambiente sufrió significativas afectaciones.

\section{Conclusiones}

El departamento del Chocó es uno de los lugares más biodiversos del mundo, así mismo cuenta con un lugar geográficamente privilegiado que permite la reproducción de un sin número de especies vegetales y animales, si bien la ley 1448 de 2011 ley de víctimas, no reconoce al medio ambiente como tal, existen unos factores que son determinantes para darle dicha connotación, como lo son la deforestación y la minería causada por grupos al margen de la ley, además de que la constitución colombiana de 1991 es llamada la constitución ecológica, también contamos con la sentencia T- 622 de 2016 emitida por la honorable corte constitucional la cual reconoce el Rio Atrato, el más importante del departamento del Chocó como sujeto de derecho, por ser afectado por la minería; sin duda alguna el departamento del Chocó es un territorio afectado por la violencia y por disputas del territorio que convierten el entorno y su medio ambiente en una víctima más del conflicto.

De lo anterior nos preguntamos ¿qué componentes se deben tener en cuenta para la protección al medio ambiente, y brindarle una verdadera reparación real e integral a la víctima del conflicto armado, atendiendo que uno de los componentes que los estándares internacionales han determinado esta la satisfacción? Pues consideramos que se deberán tenerse en cuenta los siguientes aspectos: 
a) territorio de uso y ocupación ancestral, b) saneamiento territorial, c) implementación y apoyo económico para actividades de subsistencia como son la agricultura, la pesca, la caza y la recolección de productos d) Apoyo, capacitación y acompañamiento para la explotación de los recursos naturales para poder hablar de un desarrollo sostenible al que se refiere el artículo 3 de la ley 99 del 1993.

Así mismo, se deben aplicar medidas tendientes a mitigar las afectaciones al ambiente y sus ecosistemas, las cuales se encuentran en el marco de la restitución, como la rehabilitación de pasivos ambientales, monitoreo de recursos ambientales y ecosistemas.

\section{Referencias}

Agudelo, F. (2001). El Pacífico colombiano: de "remanso de paz" a escenario estratégico del conflicto armado. Cuadernos el desarrollo rural. Recuperado de: https://facebook.ereportz.com/Apps/uploads/fileshare/uploads/2312-8039-1-PB1366819617.pdf

Arboleda, A (2014). La conciliación. Una mirada desde la bioética y la virtud de la prudencia. Revista Lasallista de Investigación. 11 (1). 192-202.

Así depredan los bosques en Colombia. (2017). Revista Semana. Recuperado de: http://mww.semana.com/ nacion/articulo/la-crisis-por-deforestacion-de-bosques-en-colombia/537101

Bello, J. C., Báez., M. Gómez, M. F., Orrego, O. \& Ñägele, L. (2014). Estado y tendencias de la biodiversidad continental de Colombia. Instituto Alexander Von Humbold. Bogotá D.C., Colombia.

Botero, C. (2010). El Choco Biogeográfico, un tesoro de la naturaleza. Eco portal. Net. Recuperado de: https:// www.ecoportal.net/temas-especiales/biodiversidad/el_choco_biogeografico_un_tesoro_de_la_naturaleza/

Comisión Histórica del Conflicto y sus Víctima. (2015). Contribución al entendimiento del conflicto armado en Colombia. Recuperado de: http://www.altocomisionadoparalapaz.gov.co/mesadeconversaciones/ PDF/Informe\%20Comisi_n\%20Hist_rica\%20del\%20 Conflicto\%20y\%20sus\%20V_ctimas.\%2OLa\%2OHabana\%2C\%20Febrero\%20de\%202015.pdf

Comité Internacional de la Cruz Roja [CICR]. (2008) ¿Cuál es la definición de "conflicto armado" según el derecho internacional humanitario? Recuperado de: https://mww.icrc.org/spa/resources/documents/article/ other/armed-conflict-article-170308.htm

Comité Internacional de la Cruz Roja [CICR]. (2008). Conflictos en el mundo que están activos hoy en día. Recuperado de: https://eacnur.org/blog/conflictos-mundo-activos-hoy-dia/.

Congreso de Colombia. (19 de diciembre de 1973). Por el cual se conceden facultades extraordinarias al Presidente de la República para expedir el Código de Re- 
cursos Naturales y de Protección al Medio Ambiente y se dictan otras disposiciones. [Ley 23 de 1973]. DO: 34.001 .

Congreso de la República de Colombia. (10 de junio de 2011). "Por la cual se dictan medidas de atención, asistencia y reparación integral a las víctimas del conflicto armado interno y se dictan otras disposiciones. [Ley 1448 de 2011].

Congreso de la República de Colombia. (23 de diciembre de 1993). "Por la cual se crea el Ministerio del Medio Ambiente, se reordena el Sector Público encargado de la gestión y conservación del medio ambiente y los recursos naturales renovables, se organiza el Sistema Nacional Ambiental, SINA, y se dictan otras disposiciones". [Ley 99 del 1993].

Constitución Política de Colombia (1991). Legis, 2da Edición.

Convención Americana de Derechos Humanos (1988). A-52: Protocolo Adicional A La Convención Americana Sobre Derechos Humanos En Materia De Derechos Económicos, Sociales Y Culturales, "Protocolo De San Salvador".

Corte Constitucional Colombiana, Sala Plena. (8 de febrero de 2012). Sentencia C-052 de 2012. MP. Nilson Pinilla Pinilla.

Corte Constitucional Colombiana, Sala sexta de Revisión. (10 de noviembre de 2016). Sentencia T - 622 del 2016. MP. Jorge Iván Palacio Palacio.

El colombiano (2015). El medio ambiente: otra víctima silenciosa del conflicto. Recuperado de: http://mww. elcolombiano.com/colombia/el-medio-ambiente-otra-victima-silenciosa-del-conflicto-GX1189844.

El medio ambiente es clave para el posconflicto: ONU Medio Ambiente. (2017). Revista Semana. Recuperado de: http://sostenibilidad.semana.com/medio-ambiente/articulo/medioambiente-es-clave-para-el-posconflicto-onu-medio-ambiente/37385

En 2017 aumentó el abismo entre millonarios y pobres. (2017). El Tiempo. Economía. Recuperado de: https:// www.eltiempo.com/economia/sectores/desigualdad-aumento-en-el-2017-y-la-brecha-entre-ricos-y- pobres-175900

Espinosa, N. (2012). Impactos del paramilitarismo en la región Rabá/Chocó 1998-2006. Claves para la lectura de las afectaciones colectivas. El Ágora U.S.B., 12(2), 287-327.

Fajardo, D. (2015). Comisión Histórica del conflicto y sus víctimas. Estudio sobre los orígenes del conflicto social armado, razones de su persistencia y sus efectos más profundos en la sociedad colombiana. Disponible en https://mww.centrodememoriahistorica.gov. co/descargas/comisionPaz2015/FajardoDario.pdf

Farc ocasionaron emergencia ambiental en Putumayo tras derramar petróleo de 23 carrotanques. (2015). RCN Noticias. Recuperado de: https://noticias.canalrcn.com/nacional-regiones-sur/emergencia-ambiental-putumayo-hombres-armados-vertieron-el-petroleo-23

Fundación Paz \& Reconciliación. (2010). Observatorio del programa presidencial de Derechos Humanosy Derecho Internacional Humanitario. Recuperado de: http://historico.derechoshumanos.gov.co/Observatorio/Publicaciones/documents/2010/Estu_Regionales/04_03_regiones/choco.pdf

Ideam (2017). Esfuerzos del país se concentran en alcanzar meta de 0 deforestación. Recuperado de: http://www.ideam.gov.co/web/sala-de-prensa/noticias/-/asset_publisher/96oXgZAhHrhJ/content/ esfuerzos-del-pais-se-concentran-en-alcanzar-meta-de-O-deforestacion

Instituto Humboldt (2017). ¿Cara o sello? Conflictos ambientales en el posacuerdo. Recuperado de: http:// humboldt.org.co/es/actualidad/item/1038-conflictos-ambientales-posacuerdo.

López, C. (s.f). Monografía Político Electoral Departamento De Chocó 1997 A 2007. Recuperado de: https:// moe.org.co/home/doc/moe_mre/CD/PDF/choco.pdf

Manfred, T. (2016). El medio ambiente: otra víctima silenciosa del conflicto armado en Colombia. Semana Rural. Recuperado de: https://semanarural.com/ web/articulo/el-medio-ambiente:-otra-victima-silenciosa-del-conflicto-armado-en-colombia/216 
Molano, A. (2010). Fragmentos de la Historia del Conflicto Armado. Recuperado de: http://www.altocomisionadoparalapaz.gov.co/mesadeconversaciones/ PDF/fragmentos-de-la-historia-del-conflicto-armado-1920-2010-1447167631-1460380435.pdf

Organización de las Naciones Unidad [ONU]. (1972). Declaración de Río sobre el Medio Ambiente y el Desarrollo. Recuperado de: http://www.un.org/spanish/ esa/sustdev/documents/declaracionrio.htm

Organización de las Naciones Unidad [ONU]. (1972). Declaración De La Conferencia De Las Naciones Unidas Sobre El Medio Humano. Estocolmo, Recuperado de: https://uww.dipublico.org/conferencias/ mediohumano/A-CONF.48-14-REV.1.pdf

Organización de las Naciones Unidad [ONU]. (1992). Declaración de Río sobre el Medio Ambiente y el Desarrollo. Recuperado de: http://mww.un.org/spanish/ esa/sustdev/documents/declaracionrio.htm

Presidencia de la República de Colombia. (1984). Decreto 1594 del 26 de junio de 1984 "Por el cual se reglamenta parcialmente el Título I de la Ley 9 de 1979, así como el Capítulo II del Título VI -Parte III- Libro II y el Título III de la Parte III -Libro I- del Decreto - Ley 2811 de 1974 en cuanto a usos del agua y residuos líquidos". Bogotá: Presidencia.

Presidencia de la Republica. (18 de diciembre de 1974). Por el cual se dicta el Código Nacional de Recursos Naturales Renovables y de Protección al Medio Ambiente. [Decreto 2811 de 1974]. DO: 34.243.

Presidente de la República de Colombia. (9 de diciembre de 2011). "Por el cual se dictan medidas de asistencia, atención, reparación integral y de restitución de tierras a las víctimas pertenecientes a comunidades negras, afrocolombianas, raizales y palenqueras" [Decreto-Ley 4635 de 2011].

Red Nacional De Información (2017). Registro único de víctimas. Recuperado de: https://rni.unidadvictimas. gov.co/RUV

Redacción Vivir. (2015). "El 58\% de la deforestación colombiana ocurre en municipios de conflicto". El espectador. Recuperado de: http://www.elespectador. $\mathrm{com} /$ noticias/medio-ambiente/el-58-de-defores- tacion-colombiana-ocurre-municipios-de-articulo-602880

Restrepo, V. (1988). Estudio sobre las minas de oro y plata de Colombia. Disponible en: http://www.banrepcultural.org/blaavirtual/historia/minas/indice.htm

Rodríguez, G. (2016). "Un deshonroso podio para Colombia". Semana sostenible información que lleva a la acción. Recuperado de: http://sostenibilidad.semana.com/opinion/articulo/un-deshonroso-podio-para-colombia/36270

Serra-Horguelin, A. \& Schoeller, D. 2014. Chocó: Entre La Extracción y El Olvido. Fundación Universitaria Clarentana. Recuperado de: https://choco.org/choco-entre-la-extraccion-y-el-olvido/

Subgerencia Cultural del Banco de la República. (2015). El medio ambiente. Disponible en: http://www.banrepcultural.org/blaavirtual/ayudadetareas/ciencias/ medio_ambiente

UNESCO. (1989). Glosario de términos sobre medio ambiente. Recuperado de: http://unesdoc.unesco.org/ images/0008/000855/085533SB.pdf

Unidad para la atención y reparación integral a las victimas (2012). Chocó: Informe Departamental de Hechos Victimizantes a 2012. Recuperado de: https:// rni.unidadvictimas.gov.co/sites/default/files/Documentos/Choc\%C3\%B3.pdf

Vincenti, R. (s. f). Conceptos y relaciones entre naturaleza, ambiente, desarrollo sostenido y resiliencia. Recuperado de: http://observatoriogeograficoamericalatina.org.mx/egal12/Teoriaymetodo/Conceptuales/21. pdf

Yaffe, L. (2011). Conflicto armado en Colombia: análisis de las causas económicas, sociales e institucionales de la oposición violenta. Revista CS en Ciencias Sociales. 8. 187-208.

2018, Vol. 12(23) 127-144 @The Author(s) 2018 Reprints and permission: www.americana.edu.co

https://www.coruniamericana.edu.co/publicaciones/ojs/index.php/pensamientoamericano/index 